\title{
Cholinergic treatment of an amnestic man with a basal forebrain lesion: theoretical implications
}

\author{
A Chatterjee, M K Morris, D Bowers, D J Williamson, L Doty, K M Heilman
}

\begin{abstract}
Cholinergic deficient states, such as in Alzheimer's disease, are associated with amnesia. Therapeutic trials with cholinergic augmentation in Alzheimer's disease have had only equivocal results, but mechanisms other than cholinergic deficiency may contribute to the memory deficit. Normally the diagonal band of Broca provides much of the hippocampal cholinergic input. To learn if amnesia secondary to cholinergic deficiency can be ameliorated by cholinergic augmentation, we treated an amnestic man who had a lesion located primarily in the right diagonal band of Broca with physostigmine and lecithin. During the initial best-dose-finding phase, he demonstrated an inverted U-shaped curve for immediate recall of word lists, with peak performances at 3.0 and $3.5 \mathrm{mg}$ of physostigmine. Single photon emission tomography showed decreased blood flow in the medial temporal region ipsilateral to the lesion at baseline, with a reversal of the asymmetry on $3.5 \mathrm{mg}$ of physostigmine. A follow-up doubleblind, placebo-controlled study on 3.5 mg of physostigmine, however, failed to demonstrate that cholinergic treatment improved memory.
\end{abstract}

(F Neurol Neurosurg Psychiatry 1993;56:1282-1289)

University of Florida College of Medicine, Gainesville, Florida, USA

Department of Neurology

A Chatterjee

D Bowers

L Doty

K M Heilman

Department of

Psychiatry

M K Morris

Department of Clinical Psychology D J Williamson

Neurology Service, Department of Veterans Affairs Medical Center, Gainesville, Florida, USA

D Bowers

K M Heilman

Correspondence to: A Chatteriee, Department of Neurology, University of Alabama, UAB Station, Birmingham, AL 35294 USA.

Received 6 July 1992 and in revised form 3 December 1992.

Accepted 22 January 1993
The high prevalence of Alzheimer's disease has led to an extensive starch for therapeutic agents that might reverse the observed cognitive impairments. If a cholinergic deficiency can cause amnesia and patients with Alzheimer's disease who are amnestic have a cholinergic deficiency, then cholinergic augmentation would potentially reverse or ameliorate the memory disorder. This logic has resulted in numerous clinical trials using drugs to augment the cholinergic system. Perhaps the most extensive experience to date has been with physostigmine, and the results have been equivocal. ${ }^{8-10}$ Patients respond in a variable manner, and reports of efficacy of this drug are not consistently replicated." Even when memory improvement has been reported, the results have been modest and of dubious clinical significance.

The efficacy of cholinergic augmentation in Alzheimer's disease may be limited because mechanisms other than cholinergic deficiency contribute to the amnesia in this disease. Patients are also deficient in other neurotransmitters including noradrenaline, serotonin and somatostatin. ${ }^{12}$ Noradrenaline may also play a role in the modulation of memory and learning. ${ }^{13}$ The relative contributions of other neurotransmitters lost in Alzheimer's disease to memory functioning is not well understood. If they do play a modulatory role, then cholinergic augmentation alone may be inadequate to reverse a memory deficit. A second reason for the inadequacy of cholinergic augmentation in the treatment of amnesia in Alzheimer's disease may be functional consequences of the neuropathologic topography in the disease. ${ }^{14}$ Senile plaques and fibrillary tangles are found in high concentrations in the dentate gyrus and the subiculum. The dentate gyrus provides the major input to the hippocampus via the perforant pathway, and the subiculum provides the major output of the hippocampus. The hippocampus itself is a critical structure for normal memory functioning, ${ }^{15}$ and location of structural neuropathology at its major input and output sites may effectively isolate it from the rest of a larger scale neural network mediating memory. Cholinergic replacement would not alter this structural pathology, and therefore the memory improvement, if any, would be modest.

We recently had the opportunity to study a densely amnestic man with a discrete lesion primarily located at the right diagonal band of Broca. ${ }^{16}$ As the diagonal band of Broca provides much of the cholinergic input to the 
Figure 1 Axial (a), coronal (b) and sagittal (c) slices of MRI scan, showing postsurgical lesion in the right basal forebrain
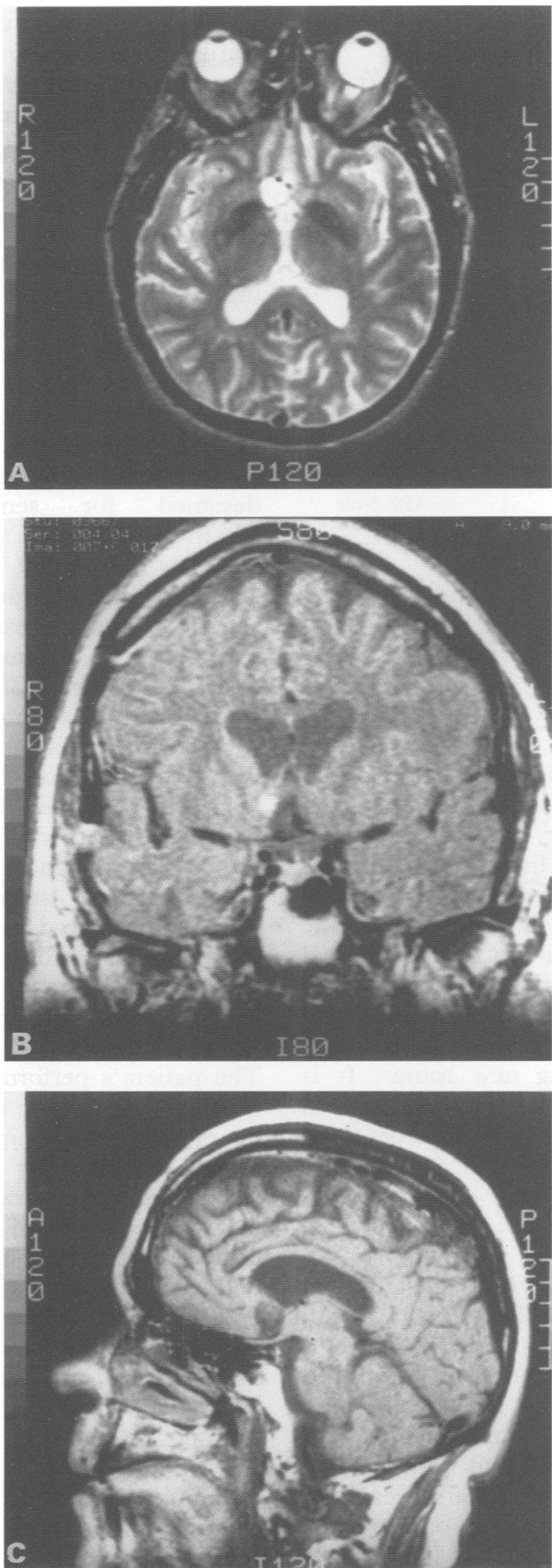

hippocampus, ${ }^{17}$ it is likely that his amnesia resulted from a cholinergic deficiency within the septal-hippocampal circuit. In the absence of a prior history of dementia, it is unlikely that he had pathological neuronal loss in the locus coeruleus or dorsal raphe with consequent noradrenergic or serotonergic deficiencies. It is also unlikely that he had accumulations of senile plaques or neurofibrillary tangles contributing to cognitive impairment. For these reasons, he provided an unusual opportunity to learn if dense amnesia as a consequence of a specific cholinergic deficiency can be ameliorated by cholinergic augmentation. The study was conducted in two phases, an open best-dose finding phase, followed by a double-blind, placebo-controlled trial on his best dose. A third phase of the study, which would have included a double-blind, two week "on", two week "off" period was planned, but was not carried out because the patient died. During the first phase of the study, he also had single photon emission tomography (SPECT) at baseline, and on physostigmine.

\section{Case report}

A 52-year-old, right-handed man had a 25year history of poorly controlled, partial complex seizures. MRI revealed a small mass lesion in the right medial basal forebrain thought to be consistent with a low grade glioma. His case history and neuropsychological testing have been reported in detail elsewhere. ${ }^{16}$ In brief, he underwent surgery for this mass lesion. A $1 \times 1.5 \mathrm{~cm}$ mass consistent with a low grade, microcystic astrocytoma was resected just posterior to the right gyrus rectus. After surgery the patient had a dense amnesia associated with confabulation.

Postsurgical MRI revealed a small discrete lesion primarily confined to the basal forebrain, right of midline (fig 1). The lesion was localised to the diagonal band of Broca, the anterior hypothalamus, the preoptic area, the paraterminal gyrus, and the lamina terminalis. ${ }^{16}$ There was minimal improvement in his memory 18 months after surgery.

BASELINE NEUROPSYCHOLOGICAL ASSESSMENT The results of comprehensive neuropsychological evaluation, before the physostigmine trial, showed intellectual function to be within the normal range (tables 1 and 2). ${ }^{18-29}$ Significant anterograde amnesia was evident on both verbal and nonverbal measures. Remote memory impairment for public events was present. He was also impaired on a test of autobiographical memory that was constructed with the help of family members. With the exception of decreased verbal fluency and mild anomia, his performance on other neuropsychological tasks was within normal limits.

Despite the right-sided lesion, his recall of verbal material was poorer than of nonverbal material. It is possible that he had changes in lateralisation as a consequence of the prolonged period of poorly controlled seizure activity. Direct comparison of performance

Table 1 Neuropsychological assessment

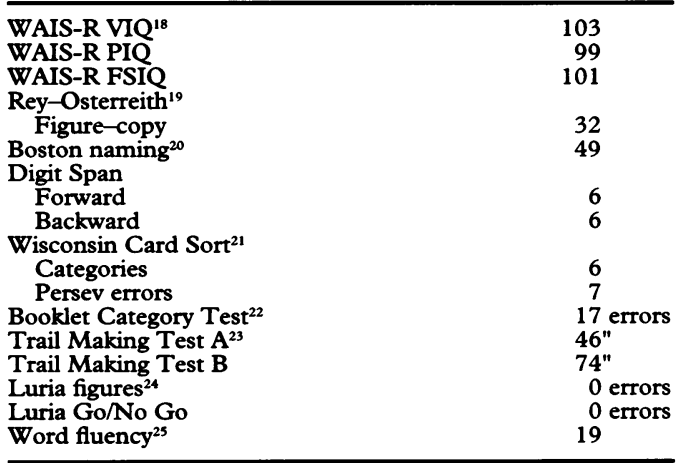


Table 2 Memory assessment

\begin{tabular}{|c|c|}
\hline \multirow{2}{*}{\multicolumn{2}{|c|}{$\begin{array}{l}\text { Wechsler } M^{26} Q^{26} \\
\text { Logical memory }\end{array}$}} \\
\hline & \\
\hline Immediate & 7 \\
\hline Delay & 0 \\
\hline \multicolumn{2}{|c|}{ Visual reproduction } \\
\hline Immediate & 7 \\
\hline Delay & 5 \\
\hline \multicolumn{2}{|c|}{ California Verbal Learning ${ }^{27}$} \\
\hline Trial 1 & 5 \\
\hline Trial 5 & 8 \\
\hline Short delay & 3 \\
\hline Long delay & 2 \\
\hline Recognition & 11 \\
\hline False + errors & 4 \\
\hline Persev errors & 0 \\
\hline Intrusions & 19 \\
\hline Cluster score & 8 \\
\hline Milner faces ${ }^{28}$ & 8 \\
\hline \multicolumn{2}{|l|}{ Rey-Osterreith ${ }^{19}$} \\
\hline Immediate & $<10$ th \%tile \\
\hline Delay & $<10$ th \% tile \\
\hline \multicolumn{2}{|c|}{ Continuous visual memory } \\
\hline d-Prime & 45th \%tile \\
\hline Delay & $\begin{array}{l}\text { 5th \%tile } \\
\text { 28th \%tile }\end{array}$ \\
\hline \multicolumn{2}{|l|}{ Boston Retro ${ }^{29}$} \\
\hline Recall & $23 \%$ \\
\hline Recognition & $48 \%$ \\
\hline Faces & $33 \%$ \\
\hline \multicolumn{2}{|c|}{ Remote autobiography } \\
\hline Recall & $50 \%$ \\
\hline Recognition & $\begin{array}{l}83 \% \\
<10 \text { th \%tile }\end{array}$ \\
\hline
\end{tabular}

on standard verbal and nonverbal memory tasks is hindered by the inherent difficulty in equating task difficulty and sensitivity to memory impairment. His performance on nonverbal memory tasks was not normal, and the difference may simply reflect the increased difficulty/sensitivity of the verbal measures. He clearly exhibited impaired spatial memory in everyday situations-for example, recalling the location of personal possessions and learning new routes. It is possible that the amnesia that results from right and left basal forebrain lesions does not exhibit material specificity.

PHASE 1-DOSE FINDING

\section{Trial design}

The patient was admitted to the Clinical Research Center, Shands Teaching Hospital, for an open trial of oral physostigmine and lecithin. Baseline assessment was completed on day 1 . On day 2 , he received $0.5 \mathrm{mg}$ physostigmine every two hours, for a total of eight doses. Lecithin was also administered $(10.8 \mathrm{~g}$, divided into three equal doses, with meals) every day for the rest of the trial. Physostigmine was increased by $0.5 \mathrm{mg}$ per dose each day to a maximum dose of $4.0 \mathrm{mg}$ per dose. He received continuous cardiac monitoring and was observed daily for potential adverse effects.

Assessment battery

A subset of the measures obtained at baseline was selected for repeated administration during the dose-finding phase of the study.

Table 3 Phase 1-assessment battery

\begin{tabular}{l}
\hline Verbal List Learning-Trials 1-5 \\
Gordon Diagnostic System ${ }^{30}$ \\
Vigilance \\
Distractability \\
Digit Span \\
Controlled Oral Word Association ${ }^{27}$ \\
Delayed Recall of Verbal List \\
Auditory Consonant Trigrams \\
\hline
\end{tabular}

Table 3 shows measures of supraspan verbal learning, attention span, attentional vigilance, distractibility, and verbal fluency. ${ }^{27} 3031$

Multiple parallel forms were necessary for each measure included in the daily assessment battery. The California Verbal Learning Test $^{27}$ was used to assess verbal learning only at baseline. A set of parallel word lists containing 16 nouns (Bowers and Verfaellie, unpublished test) was used for daily testing. Each list was matched for mean frequency, concreteness, and imageability. ${ }^{32} 33$ Administration was identical to the verbal list learning test, with five learning trials followed by a 30 minute delayed recall. Unlike the verbal list learning test, however, these lists were not designed for semantic categorization. Alternate forms of Digit Span and the Auditory Consonant Trigrams test were created by generating random number and consonant groupings, excluding groupings that provided an obvious encoding advantage (e.g., " 2468 " or "NBC"). Four parallel forms of the Controlled Oral Word Association test were created, balancing for the verbal associative frequency correlated with specific letters. ${ }^{34}$ Each of these forms was administered twice. To assess vigilance and distractibility, the Gordon Diagnostic System ${ }^{30}$ permits two different target stimulus sequences; these were administered on alternate days. Tests were administered in a standardized order each day, after the fifth physostigmine dose.

\section{Assessment results}

The patient's performance on the verbal list learning task during eight days of increasing doses of physostigmine followed an inverted U-shaped curve (fig 2). His optimal performance on the supraspan list learning task occurred at doses of $3.0 \mathrm{mg}$ and $3.5 \mathrm{mg}$ of physostigmine every two hours. At these two doses, his maximum single trial recalls of 10 and 11 significantly exceeded his typical Digit Span score of six or seven. This level of performance had not been observed in multiple evaluations over the previous 18 months. At $1.0 \mathrm{mg}, 1.5 \mathrm{mg}$, and $4.0 \mathrm{mg}$ his performance showed a decline. We are uncertain if his performance at these doses represents a decline from baseline. His delayed recall of these lists remained severely impaired throughout the trial. His performance on measures of attention span, attentional vigilance, distractibility,

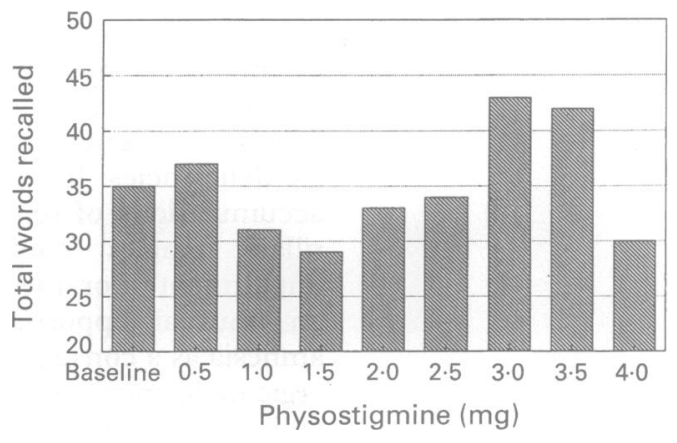

Figure 2 Immediate recall of word lists during phase 1, best-dose-finding phase. 
Table 4 Phase 2-Assessment battery

\begin{tabular}{l} 
Session 1 \\
Verbal List Learning-Trails 1-5 \\
Unfamiliar faces test-immediate recall \\
Digit Span ${ }^{18}$ \\
Digit Symbol \\
Trail Making Test ${ }^{23}$ \\
Design fluency-Part II ${ }^{35}$ \\
Verbal list learning-delayed recall \\
Unfamiliar faces-delayed recall \\
Session 2 \\
Verbal list learning-Trails $1-5$ \\
Digit Span \\
Digit Symbol \\
Trail Making Test \\
Design fluency-Part II \\
Verbal list learning-delayed recall \\
Story-immediate recall \\
Cancellation task ${ }^{36}$ \\
Proverbs test ${ }^{37}$ \\
Story-delayed recall \\
\hline
\end{tabular}

and verbal fluency did not change systematically over the eight-day trial. Cholinergic adverse effects were not observed.

PHASE 2-DOUBLE-BLIND PLACEBO TRIAL

Trial design

Evidence of enhanced memory performance in the dose-finding phase led to readmission to the Clinical Research Center for a doubleblind trial of physostigmine versus placebo. Physostigmine $(3.5 \mathrm{mg}$ ) and placebo were administered every two hours for a total of six doses over a six day period. The medication sequence (drug, placebo, placebo, drug, placebo, drug) was determined by a physician (KMH) who was not involved in the behavioural assessment and was blinded to the results during the trial. The patient and all staff involved in the assessment were blind to medication status. Lecithin was continued $(10.8 \mathrm{~g} /$ day $)$ as in phase 1 .

\section{Assessment battery}

Table 4 shows that the test battery used in phase 1 was modified for the double-blind trial. ${ }^{35-37}$ The patient received two independent evaluations each day, after the third and sixth medication dose. Tests were administered in a standardised order.

New parallel word lists were developed for phase 2 . Twelve lists of 16 nouns were created, balanced for ease of recall, based on normative data on the recall of 900 nouns. ${ }^{38}$ Two raters (AC and $M K M$ ) reviewed each list to identify any strongly associated word pairs on a single list; these were subsequently replaced.

Six parallel stories of $60-65$ words with 25 information units were created by reviewing newspapers and selecting 10 brief articles. These were modified to create passages similar to the logical memory stories of the Wechsler Memory Scale. Pilot data on the immediate recall of these 10 stories were obtained $(n=8)$. Each pilot subject's mean recall across the 10 stories and the deviation of each story from the subject's mean was computed. The six stories with the lowest average deviation from the mean across all subjects were selected.

A nonverbal memory task of six parallel sets of unfamiliar faces was created using high school yearbook photos (Bowers, unpub-

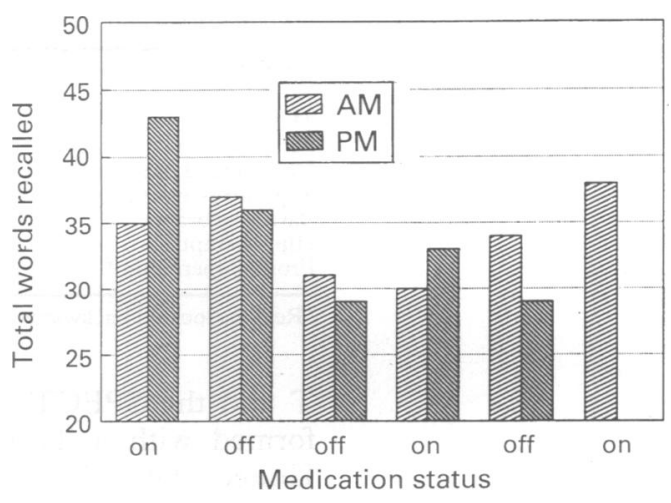

Figure 3 Immediate recall of word lists during phase 2, placebo-controlled, double-blind phase

lished test). Each set contained 12 faces, with an equal number of males and females. The task was administered in a manner similar to the Milner facial recognition test. ${ }^{28}$ The patient studied the target set of faces for 60 seconds and then selected them from a set of 24 faces, both immediately and after a 30 minute delay.

\section{Assessment results}

On the final day, before the afternoon testing, the patient began to experience nausea and vomiting. The trial was terminated, and consequently, one of the six observations in the physostigmine condition could not be obtained.

His immediate and delayed recall performance on the verbal learning task was not significantly improved by physostigmine compared with placebo (fig 3 ). He immediately recalled an average of 8 faces on physostigmine and $7 \cdot 3$ on placebo, and 6.3 (6 is a chance performance) on delay for both conditions. For story recall, he immediately remembered an average of 6.5 bits of information on physostigmine and 8.0 bits on placebo, and nothing in either condition after a 30 minute delay. Other cognitive tasks administered as part of the assessment battery-that is, measures of attention, psychomotor speed, generativity, and abstract thinking-were similarly unaffected by physostigmine.

\section{Single photon emission computer tomography}

Patients with basal forebrain lesions may have decreased metabolic activity in medial temporal structures. ${ }^{39}$ Patients with Alzheimer's disease on physostigmine have increases in blood flow, ${ }^{40}$ particularly in regions known to be cholinergically deficient. ${ }^{41}$ Because of this patient's diagonal band lesion, we anticipated that on functional imaging he would have decreased activity in the right medial temporal lobe. On physostigmine, this region would be expected to potentially demonstrate a reversal of relative left/right asymmetry.

\section{APPARATUS}

MRI measurements were performed with a Seimans (Erlangen, Germany) Magnetom 1.5 
Table 5 SPECT scan gamma count percent asymmetries: $((L-R) / L) \times 100$

\begin{tabular}{lrr}
\hline Control region of interest & Pre-treatment & \multicolumn{1}{c}{ Post-treatment } \\
\hline Motor strip & $5 \cdot 2(\mathrm{~L}>\mathrm{R})$ & $12.9(\mathrm{~L}>\mathrm{R})$ \\
Sensory strip & $8.5(\mathrm{~L}>\mathrm{R})$ & $1.2(\mathrm{~L}>\mathrm{R})$ \\
Dorsolateral pre-frontal & $25.0(\mathrm{~L}>\mathrm{R})$ & $31.0(\mathrm{~L}>\mathrm{R})$ \\
Superior temporal gyrus & $24.4(\mathrm{~L}>\mathrm{R})$ & $16.4(\mathrm{~L}>\mathrm{R})$ \\
Basal forebrain & $19.3(\mathrm{~L}>\mathrm{R})$ & $21.9(\mathrm{~L}>\mathrm{R})$ \\
Hippocampus & $17.3(\mathrm{~L}>\mathrm{R})$ & $-40.7(\mathrm{R}>\mathrm{L})$ \\
Frontal operculum & $35.8(\mathrm{~L}>\mathrm{R})$ & $44.0(\mathrm{~L}>\mathrm{R})$ \\
\hline
\end{tabular}

$T$ and the SPECT measurements were performed with a Trionics (Twinsburg, Ohio, United States) Triad 88. This system has an in-plane (transverse) reconstruction resolution of $9.3 \mathrm{~mm}$ full width half maximum and a between plane (axial) resolution of $9.3 \mathrm{~mm}$ full width half maximum at the centre of the field of view. Injections (740 MBq) of technetium-99m- $d, l$-hexamethylpropyleneamine oxime ([99m $\mathrm{Tc}]-d, l$-HM-PAO) were administered before each SPECT scan.

To aid in the orientation of and localization within the scans, plastic moulding material (All-American Mold Lab (Oklahoma City, Oklahoma, United States) XL-100 Impression System) were used to make customfitted casings for copper sulphate solution markers for MRI and cobalt-57 markers for SPECT. These casings were placed within each ear and on the glabella. The matching of marker configurations between the $M R$ and SPECT images enabled close slice to slice matching.

\section{PROCEDURE}

The subject underwent two SPECT and one MRI procedures during phase 1 of the study. The first SPECT scan was made as a baseline, before the initiation of physostigmine. The second scan was made while the subject was on a dose of $3.5 \mathrm{mg}$ of physostigmine every two hours and was performed after the fourth dose. Imaging was conducted with the subject resting quietly with his eyes closed.

\section{IMAGE ANALYSIS}

MRI slices were $7 \mathrm{~mm}$ thick with a $7 \mathrm{~mm}$ center to center distance. Pixel size on the scan is $0.914 \mathrm{~mm}^{2}$. SPECT slices were similarly reconstructed so as to be $7 \cdot 12 \mathrm{~mm}$ thick with a centre to centre distance of $7 \cdot 12 \mathrm{~mm}$. Pixel size is $3.56 \mathrm{~mm}^{2}$. Analyses are based on $19 \mathrm{MRI}$ and SPECT slices acquired from the bottom marker level to the top of the brain.

Owing to the nonlinear relationship between $\mathrm{rCBF}$ and HM-PAO distribution obtained in an uncorrected SPECT scan using [ $\left.{ }^{99 \mathrm{~m}} \mathrm{Tc}\right]-d, l-\mathrm{HM}-\mathrm{PAO}$ as a tracer, images were corrected using the method described by Lassen et $a l^{42}$ using whole brain as the reference region and $a=1 \cdot 2$. Whole brain counts were determined by adding the counts in four equally spaced slices beginning just above the gyrus rectus and continuing to just above the lateral ventricles. This sum was then divided by the total number of brain pixels in those four slices to yield an index of the average counts per pixel.

Slices in which control regions of interest were located were identified by referencing the patient's MRI scan to an anatomical atlas. ${ }^{43}$ The markers were used to locate the analogous SPECT image and characterize the control regions of interest using anteriorposterior proportions from the MRI scan. The hippocampus is difficult to locate accurately on the SPECT scan and, because of its proximity to cisterns and the cerebellum, major changes in blood flow are recorded with minor changes (measured in millimetres) in estimating the region of interest. Because of this difficulty a different procedure was used. We hypothesised that a cholinergically deficient hippocampal formation would be less active on the (right) side with the lesion and change post-treatment in a way not seen in other regions of interest (perhaps reversing left/right asymmetry). If such changes occurred on the SPECT scan in the medial temporal region, we would presume that this was the hippocampal formation. Any other major asymmetries of blood flow noted on the SPECT scan not initially included as a region of interest would also be located from the MRI scan.

\section{NUMERICAL ANALYSIS}

To obtain an index that would be comparable across scans, gamma counts from each region of interest were averaged and compared to the whole brain average corrected according to Lassen et $\mathrm{l}^{42}$. These indices were then used to explore asymmetries in the various regions of interest by expressing the asymmetry in percentage differences: $((\mathrm{L}-\mathrm{R}) / \mathrm{L}) \times 100$.

\section{RESULTS}

Table 5 shows asymmetry as percentage differences noted in the various regions of interest. The SPECT results indicate that, in the region that we suspect to be hippocampal formation, at baseline there was an asymmetry, with right blood flow being lower than left. There was marked reversal of flow in this region while the patient was on physostigmine, a change that did not occur in any other control region (fig 4 on p.1288). Although not originally planned as one of our control regions of interest, there was marked asymmetry in the frontal operculum, with the right being markedly decreased compared with the left in both pre- and post-treatment scans.

\section{Discussion}

We report results of pharmacological treatment of a densely amnestic man, who had a surgical lesion primarily localised to the right diagonal band of Broca, although parts of the anterior hypothalamus were also involved. The most likely cause of his amnesia was the disruption of the septal-hippocampal circuit. ${ }^{16}$ The diagonal band of Broca has major cholinergic projections to the hippocampus, ${ }^{17}$ which are important for normal hippocampal electrophysiological functioning, ${ }^{44}$ and this septal-hippocampal circuit may be a critical cholinergic subcomponent for normal mem- 
ory functioning. Because he did not have a premorbid dementia, the patient provided an unusual opportunity to test the hypothesis that pathologic cholinergic deficiency causing amnesia can be reversed by pharmacologic cholinergic augmentation.

The therapeutic trial failed to demonstrate a reversal or dramatic improvement in the amnesia. Although there was a suggestion of improvement in supraspan immediate recall of list items during the first phase of the study, this finding was not replicated in the second phase of the study. At no point was there convincing evidence that he was able to recall much information after a delay.

Some variability in responsiveness to treatment of patients with Alzheimer's disease may relate to the bioavailability of physostigmine to the brain..$^{45}$ Although it is possible that this patient had not adequately absorbed physostigmine or that the absorbed medication did not gain entry into the central nervous system, both behavioural and SPECT data argue against this possibility. During the dose-finding phase, his response on immediate recall of word lists followed an inverted U-shaped curve, with the optimal dose being 3.0 or $3.5 \mathrm{mg}$ of physostigmine every two hours. His pattern of improvement, better verbal free recall with an unchanged digit span, is consistent with the pattern of impairment induced in normal subjects by cholinergic blockade - that is, decreased verbal recall with a normal digit span. ${ }^{46}$ Physostigmine has a narrow therapeutic window and the patient's performance is reminiscent of a dose-response curve reported by Stern, Sano and Mayeux ${ }^{9}$ in a trial of physostigmine in patients with Alzheimer's disease, who peaked at the same dose. Inverted U-shaped curves are the hallmark of dose-dependent responses for hormonal or neurochemical modulation of memory systems. ${ }^{13}$ This patient's dose-dependent curve suggests that he received maximum clinical benefit of physostigmine, and higher doses or further bioavailability would not have been better. The second line of evidence in support of the presence of CNS modulation by lecithin and physostigmine comes from his SPECT scans. Using positron emission tomography, investigators have demonstrated that there is decreased metabolic activity in medial temporal structures in patients with basal forebrain lesions. ${ }^{39}$ Patients with Alzheimer's disease have major decreases of parietotemporal cholinergic markers with concomitant reductions in regional blood flow. Treatment with physostigmine produces a focal increase in parietotemporal blood flow in these patients but not in controls. ${ }^{41}$ Consistent with these reports, before treatment, this patient had decreased activity in the medial temporal area ipsilateral to his diagonal band lesion. On a dose of $3.5 \mathrm{mg}$ of physostigmine there was a reversal of the relative activity in the right compared with the left in the medial temporal region and not in any of the control regions of interest. Although it is not possible to be certain of our hippocampal localisation, it is dif- ficult to explain why such a reversal of flow would have occurred in any adjacent region. These SPECT scans provide evidence that physostigmine did induce changes in blood flow in regions predicted, based on the neuroanatomy of his lesion. There was an unanticipated asymmetry noticed in the frontal operculum, with the right having markedly decreased blood flow both before and during treatment. It is possible that there was mechanical damage to this region from the surgical retraction of the frontal operculum that was not evident on the MRI scan. Alternatively, because the medial forebrain bundle courses through the region of the diagonal band, some ascending noradrenergic or serotonergic fibres may have been disrupted, resulting in decreased blood flow that was not affected by cholinergic augmentation.

During the dose-finding phase of the study there was the suggestion of improvement in supraspan immediate recall of word lists at physostigmine doses of 3.0 and $3.5 \mathrm{mg}$. No difference was found in the double-blind, placebo-controlled trial. The placebo-controlled trial had several methodological limitations that need to be emphasised. The patient was unwilling to be in hospital for longer than a week, allowing only three days 'on' and three days 'off' the drug. The number of times he could be tested was limited, restricting the statistical power available to test for differences. Additionally, physostigmine pharmacodynamics within the CNS may have been a factor confounding our results. Although the serum half life is less than 30 minutes, ${ }^{47}$ CNS effects may be longer and more variable. Thal et $a l^{8}$ reported that some patients with Alzheimer's disease that appeared responsive to oral physostigmine required up to 36 hours after their last dose for their test scores to return to baseline. It remains possible that on this patient's 'off' days that followed his 'on' days, he had not yet fully cleared the CNS effects of physostigmine. We were aware of these methodological limitations and had planned a third phase with a longer two week 'on', two week 'off', double-blind placebo-controlled trial, allowing a more stable chemical state, and better assessment of the effects of cholinergic augmentation on his mnemonic abilities. Two weeks after the second phase of this study, however, he suddenly had a myocardial infarction and died before the third phase was initiated. We think it highly unlikely that physostigmine contributed to his cardiac arrest, two weeks after his last dose. We were not able to do a postmortem examination. Regardless of these methodological limitations, at no time during either phase of the study was there a dramatic improvement in his delayed memory recall.

Even under optimal conditions, there are at least two reasons why this patient may have had minimal benefit from physostigmine. First, the diagonal band of Broca, besides having cholinergic projections to the hippocampus, also has significant projections that respond to $\gamma$-aminobutyric acid 

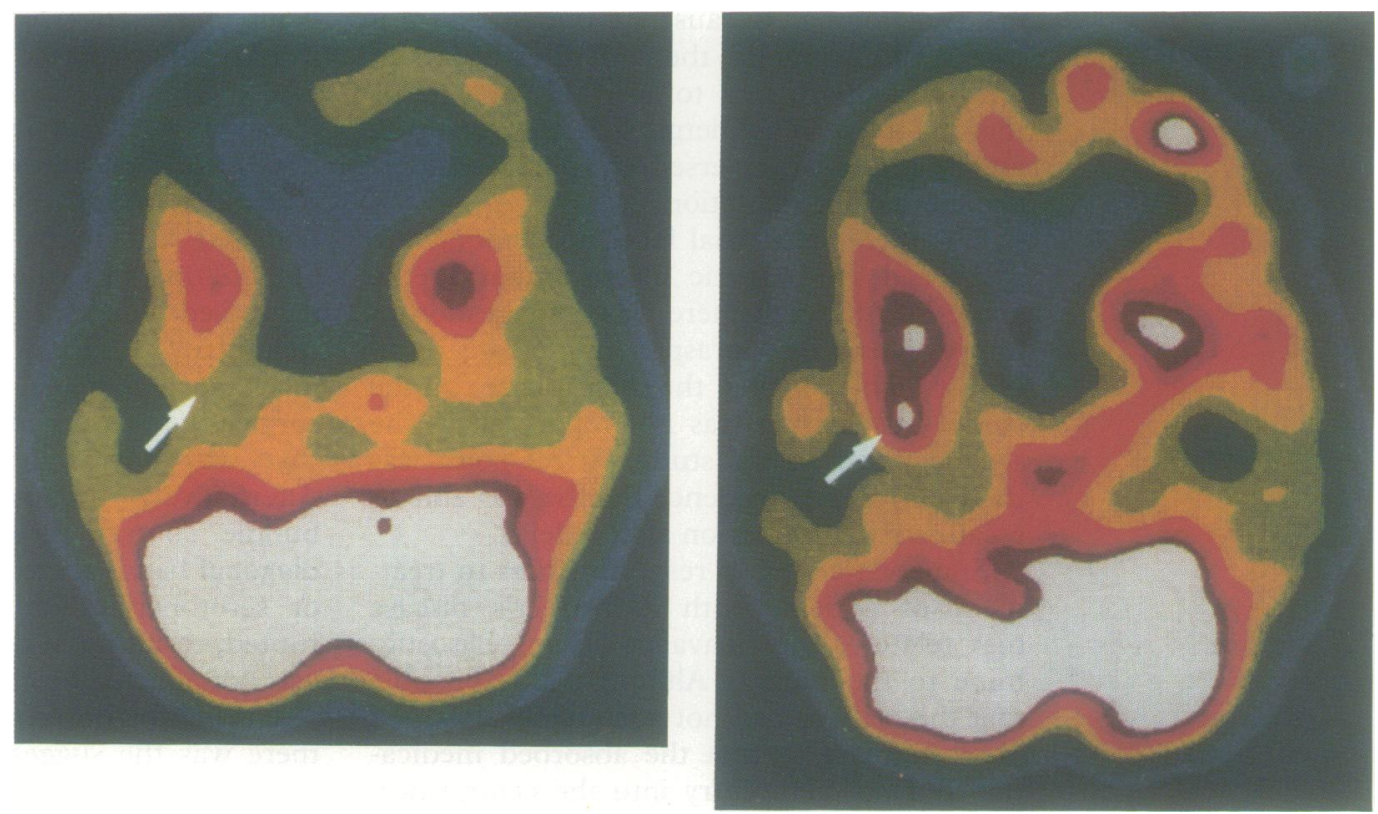

Figure 4 SPECT scan at baseline (a) and on $3.5 \mathrm{mg}$ physostigmine.

(GABA). ${ }^{17}$ GABAergic systems interact with the basal forebrain cholinergic neurons by regulating cholinergic activity ${ }^{48}$ The effects of benzodiazepines are mediated through GABA receptors, and these classes of drugs have amnestic effects that are similar to anticholinergic agents. ${ }^{49}$ The functional significance of the specific diagonal band GABAergic projections to medial temporal structures is not known. It is possible that a critical balance between cholinergic and GABAergic inputs is required for proper hippocampal functioning. Such a balance would not be achieved by simple cholinergic augmentation, limiting functional improvement.

Second, for fundamental theoretical reasons, based on how memory networks are thought to be organised, synaptic cholinergic augmentation might not serve to resurrect a memory system that is dysfunctional because of a presynaptic cholinergic deficiency. There has been recent interest in the probable parallel and distributed nature of information processing and representation in memory systems. ${ }^{5051}$ Large scale networks consisting of tightly interconnected local networks contribute to the integrity of memory processes. These local networks include the basal forebrain, medial temporal structures, and thalamic nuclei. Damasio ${ }^{50}$ has hypothesised that memory retrieval involves the reactivation of widely distributed neural structures, even including unimodal association cortices. Parts of the hippocampal formation act as a convergence zone, receiving feed-forward information from association cortices and then reactivating extra limbic structures in a feed back fashion. If principles inherent in distributed models exemplified by Damasio's proposal are biologically valid, effectively evoking a memory would involve the coordination of a specific pattern of firing with both spatial (which brain structures are activated) and temporal (in what order they are activated) characteristics. Cholinergic augmentation with physostigmine increases the synaptic concentration of acetylcholine and increases the likelihood of postsynaptic firing. A global increase in synaptic acetylcholine is unlikely to recreate specific synaptic fluctuations of acetylcholine concentration that result from a normal pattern of presynaptic neuronal firing. Simply increasing the probability of postsynaptic firing, without specific control of its temporal pattern, may be insufficient to restore hippocampal function in encoding and retrieving specific memories. It would be analogous to attempting to fix a defective Morse telegraph, by increasing the ability to transmit 'dots' and 'dashes' without being able to recreate specific patterns of 'dot' and 'dash' transmission. Despite transmission of more noise, the message contained in the pattern of transmission would still be incomprehensible.

Damage to parallel distributed networks causes a graceful degradation of function. ${ }^{51}$ This property of these systems means that with close approximations of the original activation state, the original memory might be recreated. There may be a threshold of minimal cholinergic damage in which memory impairment could be benefited by cholinergic augmentation. With damage beyond this threshold, however, synaptic cholinergic augmentation might be inadequate to recapitulate specific patterns of activation necessary to retrieve specific memories. The minimal improvement in immediate recall seen in our patient in phase 1 of the trial and reports of modest improvement in some patients with Alzheimer's disease suggest minimal upgrading of memory systems by cholinergic augmentation. Perhaps this minimal upgrading helps in immediate recall of transiently formed memory representations, representations that are too fragile to withstand dissolution over time. 
Supported in part by Clinical Research Center gran RR00082 and by the Memory Disorder Clinics of the State of Florida Departments of HRS-Elder Affairs and the Medical Research Service of the Department of Veterans Affairs.

We thank Dr. Jonathan Stewart for help in the clinical evaluation of the patient and Forest Pharmaceuticals for donation of the physostigmine and placebo tablets. We also thank Janet Wootten for editorial advice and Anne Crawford for manuscript preparation.

1 Crow TJ, Grove-White IG. An analysis of the learning deficit following hyoscine administration to man $B r f$ Pharmacol 1973;49:322-7.

2 Aigner TG, Mitchell SJ, Aggleton JP, et al. Effects of scopolamine and physostigmine on recognition memory in monkeys with isotenic-acid lesions of the nucleus in monkeys with isotenic-acid lesions of the nucleus basalis $292-300$.

3 Dunnet S. Cholinergic grafts, memory and aging. Trends Neurosci 1991;14:371-6.

4 Richardson JTE. Performance in free recall following rupture and repair of intracranial aneurysm. Brain Cognition 1989;9:210-26.

5 Damasio AR, Graff-Radford NR, Eslinger PJ, Damasio $H_{\text {, }}$ Kassell N. Amnesia following basal forebrain lesions. Arch Neurol 1985;42:263-71.

6 Whitehouse PJ, Price DL, Clark AW, Coyle JT, DeLong MR. Alzheimer disease: Evidence for selective loss of cholinergic neurons in the nucleus basalis. Ann Neurol 1981;10:122-6.

7 Perry EK, Tomlinson BE, Blessed G, Bergman K, Gibson P, Perry R. Correlation of cholinergic abnormalities with senile plaques and mental test scores in senile dementia. Br Med F 1978;2:1457-9.

8 Thal LJ, Fuld PA, Masur DM, Sharpless NS. Ora physostigmine and lecithin improves memory in Alzheimer disease. Ann Neurol 1983;13:491-6.

9 Stern Y, Sano M, Mayeux R. Effects of oral physostigmine in Alzheimer's disease. Ann Neurol 1987;22: 306-10.

10 Harrell LE, Callaway R, Morere D, Falgout J. The effect of long-term physostigmine administration in of long-term physostigmine administration

11 Wettstein A. No effect from double-blind trial of physostigmine and lecithin in Alzheimer's disease. Ann Phoul 1983;13:210-2.

12 Whitehouse PJ, Unnerstall JR. Neurochemistry of dementia. Eur Neurol 1988;28:36-41.

13 Martinez JL, Shulteis G, Weinberger SB. How to increase and decrease the strength of memory traces: The effects of drugs and hormones. In: Martinez IL Kesner RP eds. Learning and memory: $A$ biological view, 2nd edn. New York: Academic Press, 1991.

14 Hyman BT, Van Hoesen GW, Damasio A, Barnes CL. Cell specific pathology isolates the hippocampal formation in Alzheimer's disease. Science 1984;225:1168-70.

15 Zola-Morgan S, Squire LR, Amaral DG. Human amnesia and the medial temporal lesion: Enduring memory and the medial temporal lesion: Enduring memory CA1 of the hippocampus. $\mathcal{F}$ Neurosci $1986 ; 6: 2950-67$.

16 Morris MK, Bowers D, Chatterjee A, Heilman KM Amnesia following a discrete basal forebrain lesion. Brain 1992;115:1827-47.

17 Amaral DG. Memory: Anatomical organization of candidate brain regions. In: Mountcastle FP, Geiger SR, eds. Handbook of physiology. Section I. The nervous system. Volume V. Higher functions of the brain. Part I. Bethesda MD: American Psychological Society, 1987:21 1-94.

18 Wechsler D. Wechsler adult intelligence scale-revised: Manual. New York: Psychological Corporation, 1981.

19 Lezak MD. Neuropsychological assessment, 2nd edn. New York: Oxford University Press, 1983.

20 Kaplan EF, Goodglass H, Weintraub S. The Boston naming test. Philadelphia: Lea and Febiger, 1983.

21 Heaton RK. Wisconsin card sorting test. Manual. Odessa, FL: Psychological Assessment Resources, 1981.

22 DeFellipis NA, McCambell E. The booklet category test. Odessa, FL: Psychological Assessment Resources, 1979.

23 Reitan RM. Validity of the trial making test as an indication of organic brain damage. Percept Mot Skills 1958;9:127-30.
24 Luria AR. Higher cortical functions in man. New York: Oxford University Press, 1966.

25 Benton AL, Hamsher K. Multilingual aphasia examination. Manual. Iowa City: University of Iowa, 1978.

26 Wechsler D. A standardized memory scale for clinical use. 7 Psychol 1945;14:87-95.

27 Delis D, Kramer J, Kaplan E, Ober B. The Califormia verbal learning test adult version. Manual. New York: Psychological Corporation, 1987.

28 Milner B. Visual recognition and recall after right temporal lobe excision in man. Neuropsychologia 1968;6: 191-209.

29 Albert M, Butters N, Levin J. Temporal gradient in the retrograde amnesia of patients with alcoholic Korsakoff's disease. Arch Neurol 1979;36:211-6.

30 Gordon M. Gordon diagnostic system: Instructional manual. DeWitt, NY: Gordon Systems, 1987.

31 Peterson LR, Peterson MJ. Short term retention of individual verb items. F Exp Psychol 1959;58:193-8.

32 Kucera H, Francis WN. Computational analysis of present day American English. Providence, RI: Brown University Press, 1967.

33 Paivio A, Yuille J, Madigan S. Concreteness, imagery and meaningfulness values for 925 nouns. $f$ Exp Psychol 1968;67:1-25

34 Borkowski JG, Benton AL, Spreen O. Word fluency and brain damage. Neuropsychologia 1967;5:135-40.

35 Jones-Gotman M, Milner B. Design fluency: The invention of nonsense drawings after focal cortical lesions. Neuropsychologia 1977;23:658-64.

36 Albert ML. A simple test of visual neglect. Neurology 1978;23:658-64

37 Gorham DR. A proverbs test for clinical and experimental use. Psychol Rep 1956;1:1-12.

38 Christian J, Bickley W, Tarka M, Clayton K. Measures of free recall of 900 English nouns: Correlations with imagery, concreteness, meaningfullness, and frequency. Memory Cognition 1978;6:379-90.

39 Volpe BT, Herscovitch P, Raichle ME. Positron emission tomography defines metabolic abnormality in mesial temporal lobes of two patients with amnesia after rupture and repair of anterior communicating artery aneurysm. Neurology 1984;34(Suppl 1):188.

40 Hunter R, Wyper DJ, Patterson J, Hansen MT, Goodwin GM. Cerebral pharmacodynamics of physostigmine in Alzheimer's disease investigated using single photon computerized tomography. Br f Psychiatry 1991;158: 351-7.

41 Geaney DP, Soper N, Shepstone BJ, Cowen PJ. Effect of central cholinergic stimulation on regional cerebral blood flow in Alzheimer disease. Lancet 1990;335: 1484-7.

42 Lassen N, Anderson AR, Friberg L, Paulson OB. The retention of ${ }^{99 \mathrm{MTC}} d, l$-HM-PAO in the human brain after intracarotid bolus injection: A kinetic analysis. 7 Cereb Blood Flow Metab 1988;8:F13-22.

43 Damasio H, Damasio AR. Lesion analysis in neuropsychology. New York: Oxford University Press, 1989.

44 Nicoll RA. The septo-hippocampal projection. A model cholinergic pathway. Trends Neurosci 1985;8:533-6.

45 Harrell LE, Jope RS, Falgout J, et al. Biological and neuropsychological characterization of physostigmine responders and nonresponders in Alzheimer's disease. f Am Geriatr Soc 1990;38:113-22.

46 Kopelman MD, Corn TH. Cholinergic 'blockade' as a model for cholinergic depletion. Brain 1988;111: 1079-110.

47 Gibson $M$, Moor $T$, Smith $C M$, Whelpton $R$. Physostigmine concentrations after oral doses. Lancet 1985;8430:i,695-6.

48 Dudchenko P, Sarter M. GABAergic control of basal forebrain cholinergic neurons and memory. Behav Brain Res 1991;42:33-41.

49 Frith $C D$, Richardson JTE, Samuel $M$, Crow TJ McKenna PJ. The effects of intravenous diazepam and hyoscine upon human memory. $Q 7$ Exp Psychol 1984; 36A: $133-44$

50 Damasio AR. Time-locked multiregional retroactivation: A systems level proposal for the neural substrates of recall and recognition. Cognition 1989;33:25-62.

51 McClelland JL, Rumelhart DE, Hinton GE. The appea of parallel distributed processing. In: Rumelhart $\mathrm{DE}$ McClelland JL, eds. Parallel distributed processing. Exploration in the microstructure of cognition. Vol. 